\title{
Índice jornalístico da cultura em suplementos: panorâmica editorial do caderno Cultura de Zero Hora (2006-2009)
}

Journalistic index of culture in supplements: an editorial overview of Zero Hora's Cultura (2006-2009

\author{
Cida Golin \\ Universidade Federal do Rio Grande do Sul \\ Professor dos Cursos de Jornalismo e de Museologia da FABICO | UFRGS \\ Professor do Programa de Pós-Graduação em Comunicação e Informação \\ Pesquisador CNPq \\ golin.costa@ufrgs.br
}

\section{Everton Cardoso}

UFRGS

Doutorando PPGCOM|UFRGS.

Jornalista da SECOM | UFRGS.

Professor do Curso de Jornalismo da Unisinos

cardoso.everton@hotmail.com

\section{Mariana Müller}

Mariana Müller

UFRGS

Mestranda PPGCOM|UFRGS. Jornalista da TVE |RS

marianasmuller@gmail.com

\section{Mariana Sirena}

UFRGS

Mestre em Comunicação e Informação pela UFRGS.

Jornalista da OSPA-RS

sirena.mariana@gmail.com

\section{Cíntia Warmling}

UFRGS

Jornalista. Foi Bolsista de Iniciação Científica durante a realização desta etapa da pesquisa.

warmlingcintia@gmail.com 
Resumo: Este artigo apresenta uma panorâmica do caderno semanal Cultura, de Zero Hora, entre 2006 e 2009, primeira etapa de pesquisa financiada pelo CNPq. Faz a primeira leitura dos resultados quantitativos da análise de conteúdo de 1413 textos em 208 ediçóes - índices obtidos a partir da operacionalizaçáo de banco de dados criado especialmente para o trabalho. $\mathrm{O}$ espaço restritivo do suplemento evidencia a funçáo perita do jornalismo, demarca conteúdos proeminentes e seleciona o elenco de especialistas convocados a escrever uma narrativa em fragmentos sobre a cultura. O caderno analisado movimenta-se, principalmente, pelo ritmo do evento e do tempo cíclico da efeméride. Rege-se pelo valor da notoriedade e, dentro do leque eclético de temáticas, tem no mercado editorial um dos eixos de produção de pautas. $\mathrm{O}$ olhar sobre a cultura desde o sul reside especialmente na escolha dos colaboradores, vinculados às relaçóes de sociabilidade da redação e às instituiçóes regionais.

Palavras-chave: Jornalismo cultural; suplemento cultural; caderno Cultura (Zero Hora); panorâmica editorial.

Abstract: This article presents an overview of Zero Hora's weekly supplement Cultura between 2006 and 2009 - the first phase of a research project sponsored by CNPq. It brings the first interpretation of the quantitative results obtained by means of the content analysis of 1413 texts in 208 editions - indexes obtained using a database created specifically for this job. The restricted space of the supplement makes it evident the function of journalism as an expert system, defines prominent contents and selects the set of experts called to write a fragmented narrative on culture. The analyzed publication moves mainly according to the rhythm of events and the cyclic timing of anniversaries. It is ruled by the value of notoriety and, among a plethora of themes, has the editorial market as one of the axes for its agenda. The glance on culture with a southern bias is visible mainly in the choice of authors, who usually have connections to the the newsroom and regional institutions sociability.

Keywords: Cultural journalism; cultural supplement; Cultura (Zero Hora); editorial overview. 


\section{Introdução}

Na temporalidade efêmera do jornal diário, o suplemento cultural semanal é um produto segmentado que, desde sua gênese, assume a condição de dispositivo restrito: seleciona e hierarquiza temas significativos para tratamento aprofundado. O suplemento se aproxima, em parte, do conceito etimológico da revista, ou seja, do ato da re-vista, de examinar, de inspecionar mais detidamente, pressupondo o exercício da crítica e do ensaio. Ali, o jornalismo demarca espaços de conhecimento, concretizando redes de circulação dos textos artísticos e dos discursos sobre eles (BAREI, 1999). Por meio de uma temporalidade planejada e pré-agendada, em que a efeméride é pauta recorrente, o suplemento participa da construção da memória social, estabelecendo aquilo que deve ser lembrado e o modo de acionar a lembrança.

Construído na tensão entre os critérios de produção jornalística e a palavra de especialistas, o suplemento evidencia a mediação exercida pela instituição jornalística a partir de saberes de outros campos sociais, especialmente o intelectual. Ao conceder visibilidade a determinadas pautas e agentes - silenciando outros tantos -, constitui-se em mapa interpretativo do pensamento e dos valores de uma época.

Este artigo apresenta uma panorâmica editorial de quatro anos do suplemento semanal Cultura, de Zero Hora, entre os anos de 2006 e 2009. A análise do conjunto de 208 edições complementa o estudo realizado por Keller (2012) e faz parte da primeira etapa da pesquisa Jornalismo e sistema cultural: estudo da cidade no suplemento Cultura de Zero Hora (2006-2009), com financiamento do CNPq. Durante o período selecionado para este estudo, Cultura foi o único suplemento na imprensa diária do Rio Grande do Sul destinado a aglutinar intelectuais e acadêmicos, mediando saberes especializados para um público mais amplo. Em maio de 2014, foi substituído pelo caderno dominical PrOA. Neste texto, retomamos ideias desenvolvidas no percurso investigativo; em seguida, faremos uma leitura dos resultados quantitativos sobre o perfil editorial do suplemento - dados esses obtidos a partir da operacionalizaçáo de um banco de dados criado especialmente para a pesquisa -, projetando índices para a próxima etapa analítica.

\section{Visada sobre o suplemento cultural: o caso do Cultura}

OPara pensar o lugar autorizado de saber proposto pelo suplemento, é possível aproximá-lo da leitura de Miguel (1999) sobre o jornalismo como sistema perito. O autor entende que a instituição jornalística está baseada na excelência técnica e no contrato de confiança com o público, já que este não domina os mecanismos de produção da prática dos jornalistas. Na atividade rotineira e "naturalizada" da seleção, o jornalismo promove consensos e valores que conduzem a apreensão de uma realidade 
construída (MIGUEL,1999), impondo um conjunto de critérios para estabelecer o que há de "mais importante" para se saber no mundo.

Os suplementos ancoram o seu prestígio no reconhecimento dos colunistas e colaboradores, muitos deles próximos do campo acadêmico (TRAVANCAS, 2001). Por intermédio do jornalismo, esses agentes ganham crédito social, conquistam visibilidade para além do seu circuito reservado e buscam - supostamente - falar a um público mais amplo, assumindo o papel de decifradores. Na tarefa semanal de congregar um segmento de especialistas, essas publicaçóes reafirmam a cada edição que é preciso deter conhecimento sobre outros campos para selecionar o melhor e mais habilitado. O caderno especializado, portanto, funciona também como metassistema perito, ou como explica Miguel (1999), como mais um dos mecanismos para legitimar ou deslegitimar a crença nos sistemas peritos, algo já praticado de forma cotidiana e informal pelo jornalismo.

O suplemento de ZH nasceu em 13 de abril de 1967 com uma chamada na capa do jornal: "um lançamento excepcional do nosso jornal, duas vezes por mês, e que você deve colecionar". Esse posicionamento de colecionável e, portanto, como documento a ser arquivado, concede aos suplementos um sentido de permanência. Sendo o dispositivo um enunciador de significados que antecedem a leitura (MOUILLAUD, 2002), o sujeito que se aproxima dessas publicaçôes semanais já enviesa sua mira$\mathrm{da}$, tem uma expectativa de que ali estejam temas diferentes dos que se encontram no corpo principal do periódico. Suplementares, expressam 'outro' discurso dentro da publicação. No jogo de estar dentro do jornal e de também estar fora - típico da separata -, ganham vida própria, evidenciada, inclusive, pelo nome que os distingue do diário.

Sabe-se, a partir do resgate histórico realizado por Keller (2012), que a primeira versão do Caderno de Cultura de $\mathrm{ZH}$ circulou até a edição de número 60, de 11 de abril de 1970. Houve um hiato de onze anos até que outra publicação com as mesmas características voltasse ao jornal. Em 3 de outubro de 1981 foi lançado o primeiro ZH Cultura, um suplemento mensal cujo texto de apresentação destacava o perfil reflexivo, reunindo textos sobre artes, literatura e ciências humanas, com a promessa de não ser "fechado e elitista". O ZH Cultura circulou até 1991. No ano seguinte, 1992, quando Zero Hora buscava visibilidade e abrangência nacional, vários ajustes foram implementados. Surgiu, então, o Cultura como parte integrante do Segundo Caderno (caderno cultural diário de $\mathrm{ZH}$, que nomeia a editoria de cultura) e com uma alteração muito significativa: passou a ser publicado semanalmente. Quase uma década depois, em 1998, o cenário já era outro e o jornal apostava naquilo que até há bem pouco tempo o distinguiria enquanto produto no mercado: o hiperlocalismo como marca discursiva que determina a hierarquia das 
pautas, configurando uma comunidade imaginada de leitores interpelados por aspectos identitários e de pertencimento a uma regiáo (FELIPPI, 2006). Em 1998 e 2010, reformas gráficas redesenharam o suplemento que encerrou seu ciclo em 2014, quando ZH, marcando as transformaçôes editoriais do seu cinquentenário, lançou o caderno dominical ProA, reposicionando também o foco editorial de seu principal impresso.

Zero Hora é o jornal hegemônico no Rio Grande do Sul e ocupa a sexta posição entre os periódicos brasileiros. De acordo com o IVC (Instituto Verificador de Circulação), a circulação média é de 184.566 exemplares por dia contra cerca de 140 mil do concorrente Correio do Povo. Entre 2012 e 2013 sua circulação caiu 0,45\% e dados de setembro de 2014 apontam que o Diário Gaúcho - jornal também do Grupo RBS, voltado às classes C, D e E - superou a circulação de $\mathrm{ZH}$, ultrapassando os 185 mil exemplares por dia.

\section{A rede de pesquisas em jornalismo cultural e a produção do banco de dados}

O jornalismo ocupa um espaço privilegiado de mediação no sistema cultural, produz instantâneos sobre o circuito e propóe uma totalidade até então dispersa: congrega os diversos segmentos e agentes em disputa, estabelece hierarquias e valoração estética ao destacar determinados acontecimentos ou silenciar outros tantos. Nesse contexto, esta pesquisa busca problematizar como o caderno Cultura constrói jornalisticamente a representação da cidade, entendida aqui como um dos principais agentes da esfera cultural e território fundamental da experiência contemporânea. A primeira fase, contemplada neste relato, busca mapear temas, gêneros, valores-notícia e colaboradores, além de referências temporais e especiais, visualizando o perfil editorial do caderno e as principais temáticas eleitas para compreender a cultura de sua época e da comunidade a que se destina.

A investigação está inserida nas atividades do Núcleo de Estudos em Jornalismo e Publicaçóes Culturais do Laboratório de Edição, Cultura e Design (LEAD) . Desde 2007, desenvolve projetos sistemáticos com o intuito de compreender a lógica do jornalismo em relação dinâmica com o sistema cultural, especialmente em estudos de viés histórico. As pesquisas realizadas permitem conhecer períodos e experiências editoriais significativas da história da imprensa no Rio Grande do Sul, principalmente em Porto Alegre, por meio da análise de publicaçóes e da ação de agentes como jornalistas, editores e críticos. Os trabalhos oferecem uma perspectiva, ainda que em fragmentos, sobre os distintos modos de fazer jornalismo dos anos 1950 à atualidade, revisando a contribuição de jornais hegemônicos de cada período no processo de hierarquização editorial dos diversos segmentos que compóem o campo artístico e cultural. 
Em geral, as investigaçóes trabalham conjuntamente a metodologia da análise de conteúdo. Acreditamos que a sistematicidade seja um dos principais méritos desse procedimento, produzindo dados de natureza recorrente e cumulativa. Esse recurso tem sido utilizado para a construção de panorâmicas editoriais dos suplementos semanais, servindo como âncora para estudos comparativos, tanto cruzando elementos de uma mesma publicação em diferentes períodos, quanto comparando diferentes encartes (GOLIN, CARDOSO, MÜLLER, 2014). Na maioria das pesquisas, o estabelecimento das categorias está circunscrito às palavras-tema que apontam os núcleos de sentido, cuja frequência tem relação direta com o objetivo analítico perseguido (Bardin, 2011), e que acionam o jornalismo cultural tanto no caso dos suplementos semanais como no da cobertura diária.

Em 2013, o grupo criou um banco de dados informatizado, a fim de aplicar um mesmo padrão de fichamento para publicaçôes culturais com perfis semelhantes - suplementos culturais - em diferentes períodos históricos. A ferramenta garante agilidade à pesquisa, além de segurança no manuseio dos dados. Partindo do trabalho inicial feito por Keller (2012) a respeito das ediçóes de 2010 do Cultura, e avaliando as características típicas do jornalismo cultural já debatidas por ocasião de outros projetos e na literatura sobre o tema, chegou-se a um conjunto de itens a serem contemplados e que poderiam, depois de registradas todas as ediçôes, permitir cruzamentos.

A criação do banco de dados trouxe à tona tensôes típicas do estabelecimento de critérios arbitrários e comuns à análise geral de periódicos. Definir exatamente o limite do significado de cada uma das rubricas, no nosso caso, obrigou-nos a lidar com a impossibilidade de exclusão mútua, condição preconizada em parte pela metodologia. A tessitura complexa dos objetos, muitas vezes, carrega elementos que aparecem tanto em um grupo quanto em outro, tornando improdutivo fixar uma descrição a partir de contornos tão demarcados. Foi o caso, nesta experiência, de categorias como "tema" e "valores-notícia" presentes nos textos indexados. Cada unidade de categorização possui mais de um critério de seleção (atualidade, notoriedade e morte, por exemplo) ou incide em mais de uma área de conhecimento (livros, história). Nesse sentido, nos interessa mais a frequência do aparecimento desses itens do que o encaixe exato em uma classificação estanque. Por outro lado, reconhecemos o grau de subjetividade implícito no gesto interpretativo de leitura que, a cada texto lido, define escolhas e exclusôes.

\section{A descrição dos dados quantitativos}

As informaçôes gerais obtidas a partir do preenchimento do banco de dados permitem inferir as tendências e linhas editoriais do caderno 
Cultura durante os quatro anos pesquisados, entre 2006 e 2009. Foram cadastradas 208 ediçóes, totalizando 1413 textos lidos e indexados no banco.
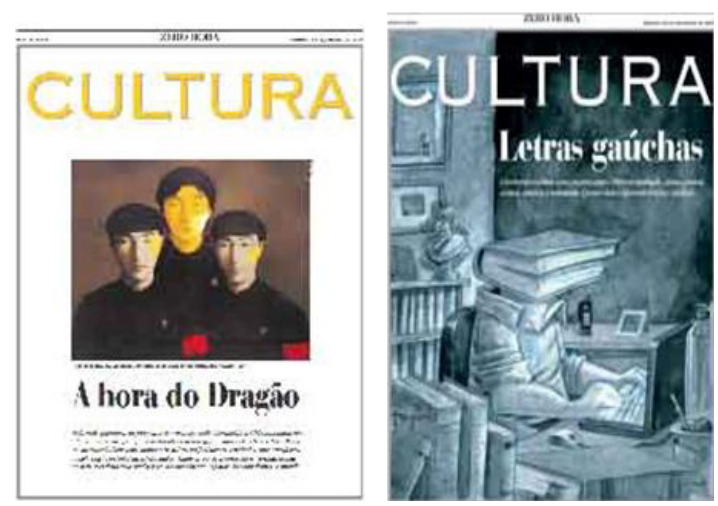

FIGURAS 1 e 2: Capas das ediçôes do suplemento Cultura publicadas em 13 de janeiro e de 29 de dezembro de 2007.

Fonte: Arquivo Zero Hora

Durante o período estudado, o caderno foi editado por vários jornalistas. Eduardo Veras esteve no comando de 75 edições $(36,05 \%$ do total), a maioria entre 2006 e 2007. Nos dois anos seguintes, o caderno passa por um período de transição, com diversos editores, sendo que Luiz Zini foi quem conduziu a maioria dos números (63 cadernos em quatro anos, $30,28 \%$ do total).

A seguir, apresentaremos os índices obtidos em torno de categorias como valores-notícia e ganchos, temas, gêneros e autores. Considerando nossas ideias preliminares - de que o suplemento cultural significa um lugar restrito e distintivo dentro do universo do jornal diário -, iniciamos a descrição e problematização dos principais valores que regem a leitura jornalística do campo da cultura. Tratamos, aqui, dos chamados valores-notícia de seleção, dentro da classificação de Traquina (2005). A partir de critérios caros e naturalizados nas rotinas de produção, o jornalismo produz um instantâneo concentrado e parcial sobre o sistema de cultura, propondo uma totalidade até então dispersa ao congregar os diversos segmentos e seus agentes em disputa

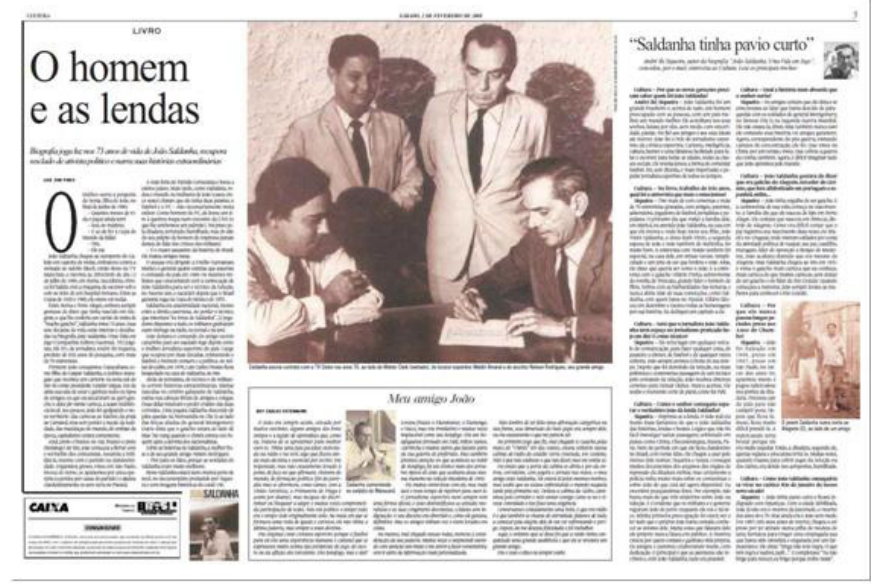

FIGURA 3: Páginas centrais do suplemento Cultura publicadas em 2 de fevereiro de 2008. Fonte: Arquivo Zero Hora 
Nessa primeira visada dos dados, organizados visualmente pelo gráfico abaixo, os valores-notícia mais frequentes são atualidade $(62,5 \%$ das matérias), notoriedade (45\%) e proximidade (21\%). É importante ressaltar que, somados, os valores de tempo (atualidade, efeméride ou continuidade) estão presentes pelo menos uma vez em 77,3\% das matérias, refletindo uma condição básica da narrativa jornalística: a pontuação e organização do tempo da cultura.

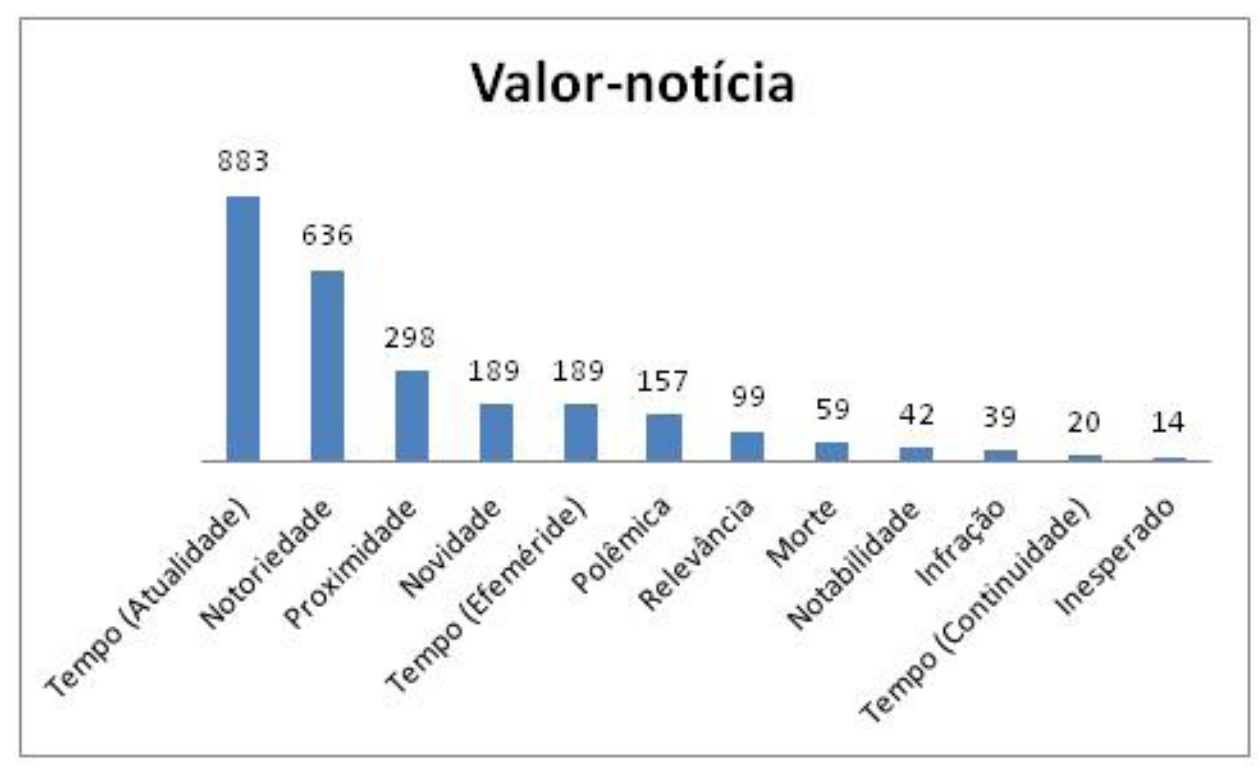

GRÁFICO 1: Incidência dos valores-notícia no conjunto de textos

No caso da cultura projetada pelo suplemento, tal marcação adquire contornos específicos. $\mathrm{O}$ acontecimento repetitivo e pré-agendado estrutura a maioria das pautas, significando o recorrente (eventos) com a visada da novidade e diferença. A efeméride é outro tempo privilegiado, presentifica o passado em ritmo cíclico e concede uma perspectiva histórica ao espaço jornalístico efêmero. Se cruzarmos esses dois valores com os ganchos de cada um dos textos, mais da metade do total carrega pelo menos um desses dois motes. Nessa leitura, o suplemento carrega um tempo previsível e provocado pelo gesto de interpretaçáo editorial, gesto esse tensionado pela exigência de ordenar a apreensão do presente e iluminar um passado que fundamenta boa parte do seu conteúdo. A efeméride sinaliza o poder do campo jornalístico de construção da memória social, de participar das disputas que definem aquilo que deve ser lembrado e o modo de acionar esta lembrança, seja pela homenagem, pelos discursos laudatórios e hiperbólicos ou por outras estratégias discursivas.

Se tudo o que tem prestígio ou capital simbólico acumulado tem maior possibilidade de se tornar visível no sistema cultural, chegamos à notoriedade, valor constitutivo do universo jornalístico. Há disposição do jornalismo cultural em afiançar artistas e obras notórias, em consagrar o setor artístico-cultural hegemônico, seja ele resultante do mercado 
ou da tradição. No caso do Cultura, essa tendência é significativa, aparecendo em quase metade dos textos. Por outro lado, a proximidade incide de forma menos previsível no corpus (apenas 21\%), sinal de que o universo de conteúdo do caderno expande o perfil editorial hiperlocalista do jornal de origem. Ao cruzar esse indício com a geografia dos ganchos jornalísticos (cidade, estado, país, regiôes), percebemos uma porção significativa de matérias (471 unidades) tendo o Brasil como âncora, pouco mais do que a cidade de Porto Alegre (320) e o estado do Rio Grande do Sul (85), levando o leitor a um percurso para além da fronteira regional.

A morte - valor central no universo jornalístico desde que cruzado com notoriedade e notabilidade -, apareceu no caderno especialmente sob forma de situaçóes pontuais, ou seja, o falecimento de sujeitos célebres, oportunidade sempre reservada para retomada de legados culturais e simbólicos. Porém, quando esse tipo de notícia foi apresentada na capa, espaço de maior relevância hierárquica, sua dimensão ultrapassou o circuito de cultura. Ganharam capas as mortes dos diretores Michelângelo Antonioni e Ingmar Bergman, ocorridas na mesma semana (edição 04.08.2007); os 25 anos do falecimento do trovador gaúcho Gildo de Freitas (01.12.2007); documentos de pesquisa que provam o extermínio do povo charrua em 1831 (12.09.2009); a violenta morte do menino João Helio em um assalto no trânsito do Rio de Janeiro (17.02.2007); e o acidente do voo 3054 da TAM no aeroporto de Congonhas, em São Paulo que repercutiu na abertura de duas edições (21.07.2007 e 28.07.2007).

\section{Amplitude temática: livros, literatura, história e intelectuais}

A multiplicidade temática - 46 temas cadastrados que incluem da política à psicanálise, do urbanismo à ecologia - indica um caderno eclético, cuja perspectiva cultural é abrangente. Porém, os principais temas abordados - Livros, Literatura, História, Intelectuais e Música - acabam alinhando-o à perspectiva mais restritiva de cultura, orientada principalmente pelos eventos do circuito e pela oferta de produtos (lançamentos). Livros (Mercado Editorial) é a rubrica mais frequente (29\%), seguida por Literatura (18,2\%), História (16,8\%), Intelectuais $(14,8 \%)$ e Música $(11,9 \%)$.

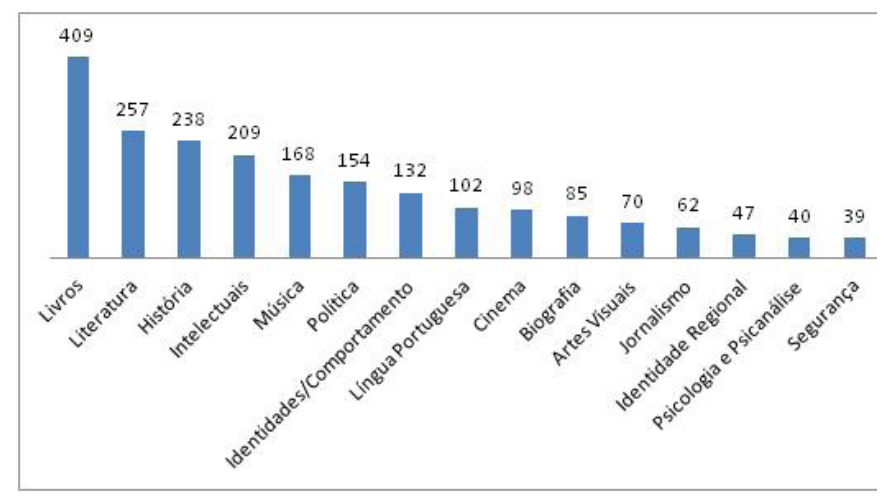

GRÁFICO 2: Quinze temas mais frequentes dentro do corpus deste estudo 
A partir da categoria livros, infere-se que o movimento do mercado de edição e lançamentos editoriais constitui um dos pilares do caderno, tanto que esse eixo está relacionado, na sua maioria (322 de 409 matérias, ou seja, $78,72 \%$ do total) ao evento como acontecimento e marcador temporal da narrativa sobre o campo da cultura. Entre os fatos cíclicos que repercutem no período, podemos citar a Feira do Livro de Porto Alegre e o Fato Literário (promoção de ZH), a Jornada Literária de Passo Fundo, Festa Literária Internacional de Paraty, e os lançamentos de livros ou intelectuais vinculados ao ciclo Fronteiras do Pensamento. Cabe salientar aqui que boa parte destes eventos tem vínculo muito próximo ou são promovidos pela própria empresa proprietária do jornal. Dentro do mercado editorial, temos a prevalência dos segmentos literatura $(29,82 \%)$, história $(15,89 \%)$, intelectuais $(15,15 \%)$, biografias $(8,06 \%)$ e jornalismo $(7,33 \%)$, tratados basicamente em formatos analíticos $(45,72 \%$ somando críticas e resenhas; ensaios e artigos) e informativos (49,87\%, considerando a grande presença de informes e notas - 22,98\% -, entrevistas e reportagens). Os autores mais recorrentes provêm da redação do jornal.

Ao longo das 208 edições analisadas, o tema livro ganhou 61 capas (29,32\%), Destacam-se, aqui, pautas relacionadas ao mercado de criação e distribuição (vendas de livro pela internet; polêmica sobre a prática de oficinas de criação literária), especialmente, a presença de sujeitos notórios da literatura e a rememoração de fatos marcantes da história, próximas categorias a serem discutidas brevemente.

Somando as rubricas livros e literatura, temos um total de 79 capas $(37,98 \%)$, mais de um terço do conjunto, inserindo Cultura na linhagem dos suplementos que sempre defenderam o protagonismo do livro, mantendo forte vínculo com a literatura e o setor editorial e constituindo-se em um recorte do mercado de edição em distintos períodos históricos (TRAVANCAS, 2001). A cobertura de literatura se rege prioritariamente pelos valores da notoriedade (177 de 257 matérias, 68,87\%), atualidade $(61,47 \%)$, efeméride $(22,95 \%)$ e proximidade $(19,84 \%)$. Esse movimento está expresso no conjunto das capas dedicadas aos temas literários (39 capas para literatura; $18,75 \%$ do total), nas quais predomina a personalização do escritor canônico e o tempo repetitivo da efeméride, destacado anteriormente, que atualiza o passado em forma de homenagem e reinsere obras no circuito de oferta e distribuição. É o caso, por exemplo, dos cem anos da morte de Machado de Assis, 80 anos de nascimento García Márquez e de Ariano Suassuna, 70 anos de Luis Fernando Verissimo e de Moacyr Scliar, entre outros. Em quatro anos, Caio Fernando Abreu ganhou duas capas por ocasiáo da organização de seu acervo e da divulgação dos manuscritos.

$\mathrm{O}$ olhar regional de $\mathrm{ZH}$ se acentua neste conjunto ao valorizar e repercutir a trajetória dos escritores nascidos no Rio Grande do Sul, do 
século XIX à contemporaneidade. Essa tendência prevalece também no miolo da cobertura, junto aos clássicos brasileiros e latino-americanos, que têm espaço garantido no suplemento. Entre os articulistas principais do segmento estáo o professor de literatura da UFRGS e colunista de ZH Luís Augusto Fischer e o repórter especializado na área Carlos André Moreira. A análise dos gêneros demonstra equilíbrio entre os formatos analíticos e os jornalísticos, porém chama atenção a pouca inserção da ficção (apenas oito recorrências ou 3,11\% do total), contrapondo-se à tendência histórica do gênero suplementar em reservar parte de suas páginas para divulgação de poesia, contos, folhetins e demais expressôes literárias e artísticas.

Também a História ganha relevo em 238 textos, ou seja, em 16,8\% do total. O tema emerge como chamada principal em 64 das 208 capas, perfazendo $30,8 \%$ do total de ediçôes, muitas vezes aglutinando mais de uma matéria sobre um mesmo assunto. Dentro do conjunto de textos, $53 \%$ (124, em número absoluto) têm como gancho lançamentos, estreias e outros eventos do campo da produção cultural. As efemérides também são marcantes, pois servem de pretexto a um quarto das matérias cuja temática está vinculada a datas emblemáticas como o centenário do escândalo político francês conhecido como Caso Dreyfus; os 40 anos do movimento de maio de 1968; e mesmo os cinco anos do então ainda recente atentado ao World Trade Center, em Nova York.

Tendo em vista o fato de que o valor-notícia atualidade encabeça a lista dos critérios de seleção típicos do jornalismo identificados nessas matérias (61\%), é possível perceber o quanto é na relação com o presente que o histórico ganha relevo. Nesse sentido, a cidade de Porto Alegre, enquanto lugar que serve de gancho jornalístico, desponta como referência principal, em 54 textos, o que perfaz 23\% das matérias com temática histórica. Servem de pauta as histórias de personagens, instituições e eventos locais, como a historiadora Sandra Pesavento, o músico Norberto Baldauf, a revista modernista Madrugada, o Theatro Sáo Pedro ou o longevo festival Porto Alegre em Cena. Aproximamo-nos, neste caso, das consideraçóes de Pio (2005) sobre o jornalismo cultural: ao organizar em narrativas determinadas representaçóes do passado da cidade, os cadernos difundem uma espécie de dever e agendamento da memória. Em forma de arquivo, criam ou reforçam marcos distintivos da cultura local, projetam um lugar de pertencimento junto um suposto leitor.

Já os intelectuais estão como tema em 209 matérias (14,8\% do total). Em consonância com a própria natureza da temática, a notoriedade dos sujeitos aparece como valor-notícia em 92,8\% dos textos que tratam desse assunto; a seguir, critérios relativos ao tempo - atualidade (presente em 57,4\% dos textos) e efeméride (em 25,4\%). Mais da metade das matérias $(111-53 \%)$ trazem eventos do campo da produção cultural. Entre 
esses, destacam-se aqueles realizados na cidade de Porto Alegre, como o já citado ciclo de conferências Fronteiras do Pensamento, assunto de 17 textos, $8,1 \%$ do total dessa categoria. Isso certamente se explica, sob o ponto de vista da pauta, pela passagem de sujeitos notórios pela cidade, caso do historiador estadunidense Robert Darnton e da escritora e crítica literária argentina Beatriz Sarlo.

Mesmo que os textos estejam ancorados no local por força dos eventos realizados na cidade, é a circulação de notórios de outras partes do Brasil e do mundo que recebe visada do suplemento. Também nesse sentido, a presença significativa de entrevistas é indício da importância dada à passagem desses sujeitos: são 51, perfazendo $24,4 \%$ desses textos. Essa predominância indica uma tentativa de aproximar o leitor de personalidades de relevância nacional e internacional que circulam pela cidade, num movimento de valorização desses eventos e sujeitos.

\section{Análise dos gêneros e o perfil jornalístico do caderno}

Ao analisar os gêneros que mais aparecem nas páginas do Cultura, fica evidente o perfil jornalístico do caderno. A reportagem predomina na publicação, somando $22,6 \%$ dos textos analisados. $O$ foco na informação se relaciona com o contexto de produção, uma vez que grande parte dos textos é de autoria de jornalistas da redação de Zero Hora, com ou sem assinatura específica. Como vimos, temos, ainda, uma escassa participação do gênero ficção. Em contrapartida, as entrevistas somam 181 e os perfis, 27.

Esse caráter informativo se opóe, em alguma medida, ao costume anterior dos suplementos de enfatizarem o ensaio, a crítica e os fragmentos literários. A categoria dos Ensaios e Artigos aparece em destaque na análise, são $16,6 \%$ do total de textos, porcentagem próxima do gênero Críticas e Resenhas (15,8\%). No entanto, ao buscar os autores que mais escreveram em cada categoria reaparecem os jornalistas de Zero Hora. Luiz Zini Pires, que foi editor do caderno, e Carlos André Moreira, repórter, foram os mais assíduos, seguidos pelo professor de literatura da UFRGS Luís Augusto Fischer, que manteve uma coluna fixa desde outubro de 2008.

Tradição em Zero Hora desde sua criação, as colunas também são uma característica importante, totalizando 203 textos (14,36\%) no período analisado. Claudio Moreno, que se dedicava a escrever sobre a língua portuguesa, e Celso Loureiro Chaves, que escrevia sobre música erudita, assinaram a maior parte das colunas. Ambas as temáticas refletem uma aproximação com o repertório da norma culta e de viés erudito. 


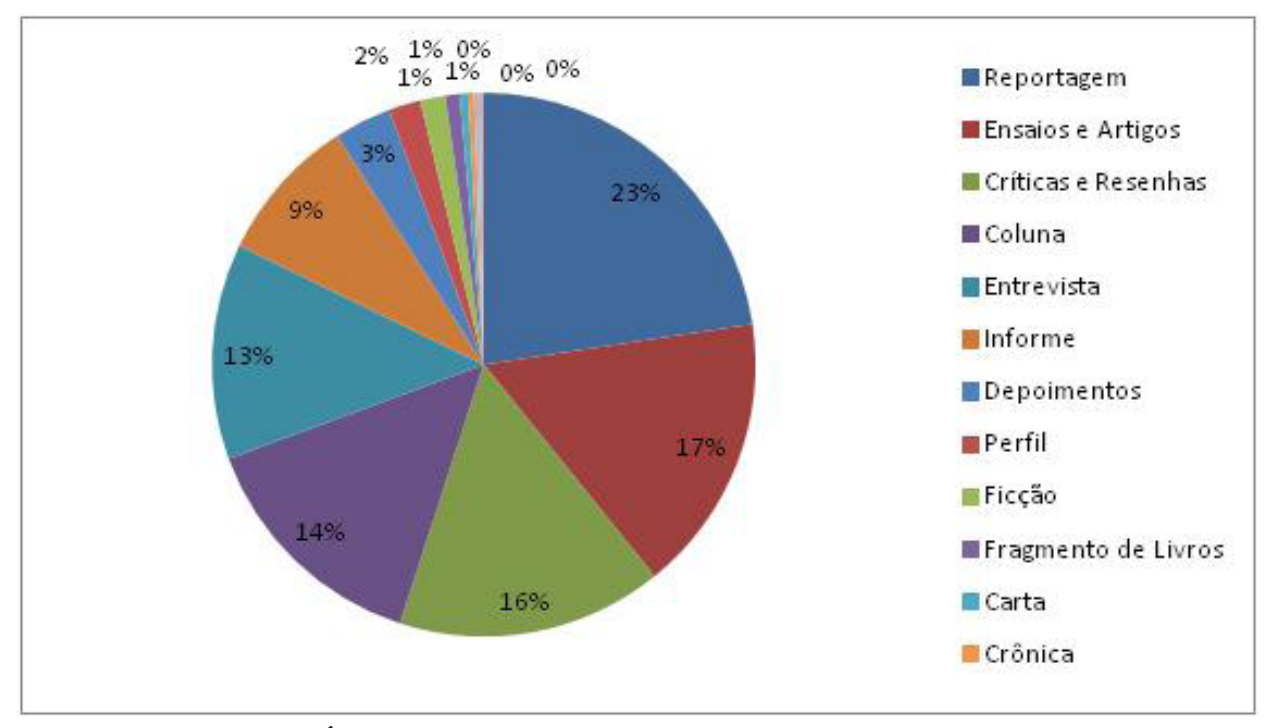

GRÁFICO 3: A incidência dos gêneros em 1413 textos

\section{Dados sobre a autoria: os laços regionais da publicação}

Os dados sobre a autoria evidenciam a redação do jornal Zero Hora como centro de produçáo do Cultura e os laços do caderno com o Rio Grande do Sul. Do total, 206 textos não têm autoria identificada e foram registrados no banco de dados como "redação", número superior a qualquer autor específico. De resto, foram contabilizados 317 autores, sendo que a grande maioria, 201, escreveu apenas uma vez no período da pesquisa. Destacam-se representantes da imprensa - são 134 jornalistas - e acadêmicos - 95 ao todo.

O centro da produção, portanto, é a própria redação, uma vez que 79 jornalistas da Zero Hora assinam textos. Carlos André Moreira, repórter de $\mathrm{ZH}$, é o principal autor individual, com 117 matérias. Ao focarmos nos 16 autores que escreveram mais de dez matérias no período, percebemos que apenas quatro não trabalham diretamente no jornal: os colunistas e professores Claudio Moreno, Celso Loureiro Chaves e Luís Augusto Fischer, além do psicanalista Mario Corso.

Fica claro, ao analisar a autoria, que existe um olhar sulista. Entre todas as pessoas que escreveram textos, 233 nasceram no Rio Grande do Sul ou têm um vínculo forte com o estado. Consideramos que mantêm uma relação fortalecida aqueles que trabalham em instituiçóes regionais, como as universidades, ou vivem há muitos anos no estado. Assim, ao todo, 73,5\% dos autores relacionam-se com o RS. É possível perceber a relação do Cultura com Porto Alegre a partir, também, das instituições de ensino que têm seus professores escrevendo artigos. Entre os acadêmicos, a maioria absoluta é da Universidade Federal do Rio Grande do Sul (43). Entre esses, os que escreveram mais de uma vez têm maior presença nas seguintes áreas: Arquitetura, Artes Visuais, Comunicação Social, Letras, História, Relações Internacionais e Economia. 


\section{Considerações finais: índices para a próxima etapa analítica}

A amplitude dos dados obtidos nesta primeira visada sobre o caderno Cultura de Zero Hora corroboram resultados alcançados por Keller (2012; 2013) na leitura das ediçóes publicadas em 2010. Somando as duas pesquisas, obtemos índices minuciosos do perfil editorial do suplemento em cinco anos consecutivos, de 2006 a 2010. Nesse período, o espaço restritivo do suplemento evidenciou a função perita do jornalismo ao demarcar conteúdos proeminentes para análise e selecionar um elenco de especialistas convocados a escrever uma narrativa em fragmentos sobre a cultura.

O caderno, aqui iluminado, movimenta-se pelo marco temporal rítmico do evento e do tempo cíclico da efeméride. Rege-se, especialmente, pelo valor da notoriedade e, apesar do leque eclético e abrangente de temáticas, tem no mercado editorial um dos eixos fundamentais de produção de pautas. A literatura, como valor artístico e simbólico, alinha o Cultura à tradição histórica dos suplementos de jornais, ainda que conceda mínimo espaço (pelo menos no período estudado) ao texto ficcional. Pelo contrário, o caderno é marcado, sobretudo, pela tensão entre formatos jornalísticos e os analíticos. A redação de Zero Hora acaba sendo o polo principal de produçáo de conteúdo e os colaboradores se dividem, em grande parte, entre aqueles situados no campo jornalístico e no acadêmico. Este último, por fim, ganha relevância como o principal perito a ser ouvido e visibilizado pelo suplemento.

A abrangência dos conteúdos e sua expansão para além da fronteira regional fazem do Cultura um contraponto ao apelo hiperlocalista do jornal de origem. Os conteúdos ultrapassam em muito a geografia circunscrita da proximidade, mesmo que os ganchos jornalísticos - a maior parte pautado pelo evento -, acusem a força e o critério do local. Nesse contexto, Porto Alegre surge como polo catalisador de um movimento de fluxos culturais (agentes, eventos e produtos) externos e internos, uma espécie de nó em um circuito intermitente. No entanto, é na escolha dos colaboradores - basicamente vinculados às relaçôes de sociabilidade da redação e às instituições regionais - que se sente o peso do olhar sobre a cultura desde o sul.

Por outro lado, a temporalidade planejada do suplemento faz dele um espaço de construção seletiva da memória e de pertencimento a um lugar investido de cultura. Acreditamos que o suplemento cultural participa da memorabilia da cidade ao selecionar e sancionar publicamente discursos da e sobre a urbe, acionando determinadas estratégias de lembrança em que a homenagem é um recurso recorrente.

Os dados obtidos até essa etapa formam uma moldura panorâmica para problematizar como o caderno Cultura de Zero Hora, produtor privilegiado de sentidos para interpretaçáo da cultura e memória citadina. Constrói, assim, uma representaçáo da cidade como agente da esfera cultural e espaço de capital simbólico e criativo. Entraremos, posteriormente, na etapa qualitativa que buscará identificar, em uma amostra selecionada do corpus, os territórios representados, entre outros elementos; será delineada, então, uma perspectiva da paisagem urbana construída pelo suplemento. No mapeamento já realizado, 
obtivemos índices e pistas relevantes de como o campo jornalístico, a partir dos seus critérios profissionais, projeta o mapa do sistema cultural local, das instâncias e agentes que instituem a cidade como espaço de capital simbólico e criativo. 


\section{Referências Bibliográficas}

Referências

BARDIN, Laurence. Análise de conteúdo. 3.ed. Lisboa, Portugal: Edições 70, 2004.

BAREI, Silvia. Periodismo cultural: crítica y escritura. Ambitos: Revista Internacional de Comunicación, Sevilha, n. 2, 1999.

FELIPPI, Angela. Jornalismo e identidade cultural: construção da identidade gaúcha em Zero Hora. 2006. 177p. Tese. (Doutorado em Comunicação Social) - Curso de Pós-Graduação em Comunicação Social, Pontifícia Universidade Católica do Rio Grande do Sul, Porto Alegre, 2006.

KELLER, Sara. Um mapa da vida cultural no Rio Grande do Sul: análise do caderno Cultura (2010), de Zero Hora. 2012. Dissertação (Mestrado em Comunicação e Informação) - Programa de Pós-Graduação em Comunicação e Informação, Universidade Federal do Rio Grande do Sul, Porto Alegre, 2012.

MIGUEL, Luis Felipe. O jornalismo como sistema perito. Tempo social: Revista de Sociologia, v. 11, n. 1, São Paulo: USP, maio de 1999.

MOUILLAUD, Maurice. O jornal: da forma ao sentido. Organização: Sérgio Dyrell Porto. 2. ed. Brasília: UnB, 2002.

PIO, Leopoldo Guilherme. Jornalismo e musealização: memória e cidade nos cadernos de cultura. Contemporânea, Rio de Janeiro, n.5, p. 83-92, 2005-02.

TRAQUINA, Nelson. Teorias do Jornalismo: por que as notícias são como são. Florianópolis: Insular, 2005, V.1.

TRAVANCAS, Isabel. O livro no jornal: os suplementos literários dos jornais franceses e brasileiros nos anos 90. Cotia: Ateliê, 2001.

\section{NOTAS}

Versão revisada de paper homônimo apresentado no $12^{\circ}$ Encontro Nacional de Pesquisadores em Jornalismo em Santa Cruz do Sul, novembro de 2014.

O autor parte de categorias propostas por Anthony Giddens em As consequências da modernidade (1991).

A pesquisa foi realizada no Centro de Documentação e Informação da RBS e no arquivo do Museu da Comunicação Hipólito José da Costa.

No intervalo, Zero Hora publicaria páginas diárias dedicadas à cultura, ao roteiro e às variedades e, no final de semana, encartes como o Guia, Revista ZH, extensa e com uma pauta eclética que abrangia temas femininos; e o Caderno D, dominical, com reportagens e textos variados. 
Dados disponíveis no portal da Associação Nacional de Jornais: www.anj.org.br/ maiores-jornais-do-brasil

Dados de junho de 2013 disponíveis no site de Zero Hora (zh.clicrbs.com.br/rs/ consultoria-tema/zh-responde-5000/jornal-impresso-5005/?pagina=2) e no portal comercial do Grupo RBS (www.comercialgruporbs.com.br/audiencia.aspx?Plataform aID=19\&MarcaID=3898).

Grupo registrado no CNPq, o LEAD integra a Faculdade de Biblioteconomia e Comunicação da Universidade Federal do Rio Grande do Sul (FABICO) e insere-se na linha de Jornalismo e Processos Editoriais do Programa de Pós-Graduação em Comunicação e Informação (PPGCOM|UFRGS).

Uma das referências foi a experiência do Núcleo de Estudos Literários \& Culturais (Nelic) da UFSC, que utiliza o chamado Sistema de Cadastro de Textos Literários em Periódicos para execução de diversas pesquisas do grupo. Ver www.nelic.ufsc.br.

O cadastro contemplou os seguintes itens: Data de Edição; Título; Chamada Principal ou Secundária; Página; Autor; Informaçóes extras do autor; Gênero do texto; Temas; Cidade | Estado | País| Região do Tema; Valor-notícia de seleção; Frases representativas dos valores-notícia; Gancho jornalístico do texto; Cidade | Estado | País | Regiáo do gancho jornalístico; Descrição da imagem; Comentários e Resumo do Texto.

Banco de dados disponível em <http://www.ufrgs.br/cadernodecultura>

Outros nomes também assinaram a editoria: Moisés Mendes, Marcio Pinheiro, Larissa Roso, Luiz Antônio Araújo, Daniel Feix, Carlos André Moreira e Ticiano Osório.

Os textos foram classificados pelos seguintes ganchos: lançamentos, estreias, eventos (655 matérias); efeméride (186); outros fatos jornalísticos (fora do campo da cultura) (162); morte (49); sem gancho (47); polêmica (47).

As categorias para a classificaçáo segundo as referências geográficas tanto dos temas quanto dos ganchos jornalísticos adotou por princípio o registro da menor unidade possível - seja ela cidade, estado, país ou região do mundo. Dessa forma, é possível trabalhar com dados mais generalizantes - se agregados todos esses índices - ou mais específicos - se mantidos tal como foram coletados. Da mesma maneira, optou-se por separar as referências geográficas dos ganchos e dos temas - já que na dinâmica do jornalismo cultural é comum um espetáculo, filme ou exposição ter uma origem portanto referência do tema - e ser apresentado ou lançado em outro lugar - local do gancho, neste caso um evento pontual.

A Feira do Livro de Porto Alegre, que ocorre em uma praça no Centro Histórico da cidade, é um evento anual e tradicional da cidade, que em 2014 realizou sua $60^{\text {a }}$ edição. O Fato Literário, por sua vez, foi um prêmio promovido pelo Grupo RBS que destacava personalidades e iniciativas da área da leitura. A primeira edição ocorreu em 2003 e a última em 2011 - com premiação em dinheiro dada aos vencedores em cerimônia durante a feira do livro. O ciclo anual Fronteiras do Pensamento também tem o apoio da RBS e sua primeira edição ocorreu em 2007. Teóricos, pensadores e 
escritores vêm até Porto Alegre para conferências pagas. Entre os nomes que já estiveram na cidade estão a argentina Beatriz Sarlo, o americano Bob Wilson, o americano David Lynch, o francês Edgar Morin, o francês Henri-Pierre Jeudy, o belga JeanPierre Lebrun, a brasileira Maria Rita Kehl, o francês Michel Maffesoli, o britânico Peter Burke, o francês Roger Chartier, o americano Tom Wolfe. A partir de 2011, o projeto também teve ediçóes em São Paulo e Florianópolis

É importante relembrar que muitas dessas capas têm em comum o tema livros e literatura. Outras apresentam somente um dos temas.

O Suplemento Literário de O Estado de S. Paulo (1956-1974), por exemplo, ficou reconhecida por ser um expoente do gênero e pelo seu papel na formação de críticos de arte no período em que circulou. Também foi espaço de visibilidade para escritores então estreantes. Em contrapartida, o Sabático (2010-2013) - suplemento focado em livros criado para resgatar a tradição do anterior - aproximou-se do Cultura na valorização do mercado editorial e na presença dos colunistas fixos.

Em seguida, aparecem a Pontifícia Universidade Católica do Rio Grande do Sul (9 textos) e a Universidade do Vale do Rio do Sinos (8). Alertamos que alguns autores não foram identificados pelo jornal e não foi possível comprovar sua procedência em função de homônimos, casos que podem provocar pequenas distorçôes nos números. 